\title{
Chordoma of the Craniocervical Junction: Endoscopic Endonasal Approach
}

\author{
Eduard H. Voormolen ${ }^{1} \quad$ Pierre Olivier Champagne ${ }^{1}$ \\ ${ }^{1}$ Service de Neurochirurgie de Prof. Froelich, Université Paris Diderot, \\ Hôpital Lariboisière, Assistance Publique-Hôpitaux de Paris, Paris, \\ France
}

J Neurol Surg B 2019;80(suppl S4):S372-S374.
Sebastien Froelich ${ }^{1}$

\begin{abstract}
Address for correspondence Eduard H. Voormolen, MD, PhD, Service de Neurochirurgie de Prof. Froelich, Université Paris Diderot, Hôpital Lariboisière, Assistance Publique-Hôpitaux de Paris, 2 rue Ambroise Paré, 75475 Paris, France (e-mail: eduard.voormolen@aphp.fr).
\end{abstract}

\begin{abstract}
Keywords

- chordoma

- craniocervical junction

- endoscopy

- endonasal

Objective This study was aimed to achieve gross-total removal of a chordoma of the craniocervical junction via an endonasal approach (-Fig. 1).

Design The present study is a case report.

Setting The study was conducted at neurosurgical clinic of university hospital.

Participant A 40-year-old male, with normal neurologic exam and no prior medical history, presented with a 2-year history of cervicalgia. On preoperative imaging, a midline lesion, with image characteristics of chordoma, was seen in the lower clivus and odontoid. It had limited lateral extension.

Main Outcome Measures This study measures postoperative neurological deficits and postoperative tumor volume on magnetic resonance imaging (MRI).

Results A binostril approach to the upper nasopharynx was performed using endoscope at 30- and 45-degree angles. Subsequently, a heart-shaped mucosal flap was made and the clivus was drilled to expose the lesion (-Fig.2). After initial debulking, the ring of $\mathrm{C} 1$ was slightly drilled to reach the tumor in and around the odontoid. Postoperative MRI showed that a gross-total resection was achieved. The patient had no neurologic deficits postoperatively. Pathologic examination revealed a chordoma of the classical type.

Conclusion An endoscopic endonasal approach, utilizing the heart-shaped flap and angled endoscopes and instruments, can be considered for resection of select cases of craniocervical junction chordoma with limited lateral expansion.

The link to the video can be found at: https://youtu.be/rwVoZJRBIEo.
\end{abstract}

www.thieme.com/skullbasevideos

www.thieme.com/jnlsbvideos

DOI https://doi.org/

10.1055/s-0039-1697979.

ISSN 2193-6331. (c) 2019 Georg Thieme Verlag KG
Stuttgart · New York

License terms

c) $(1) \$$ 


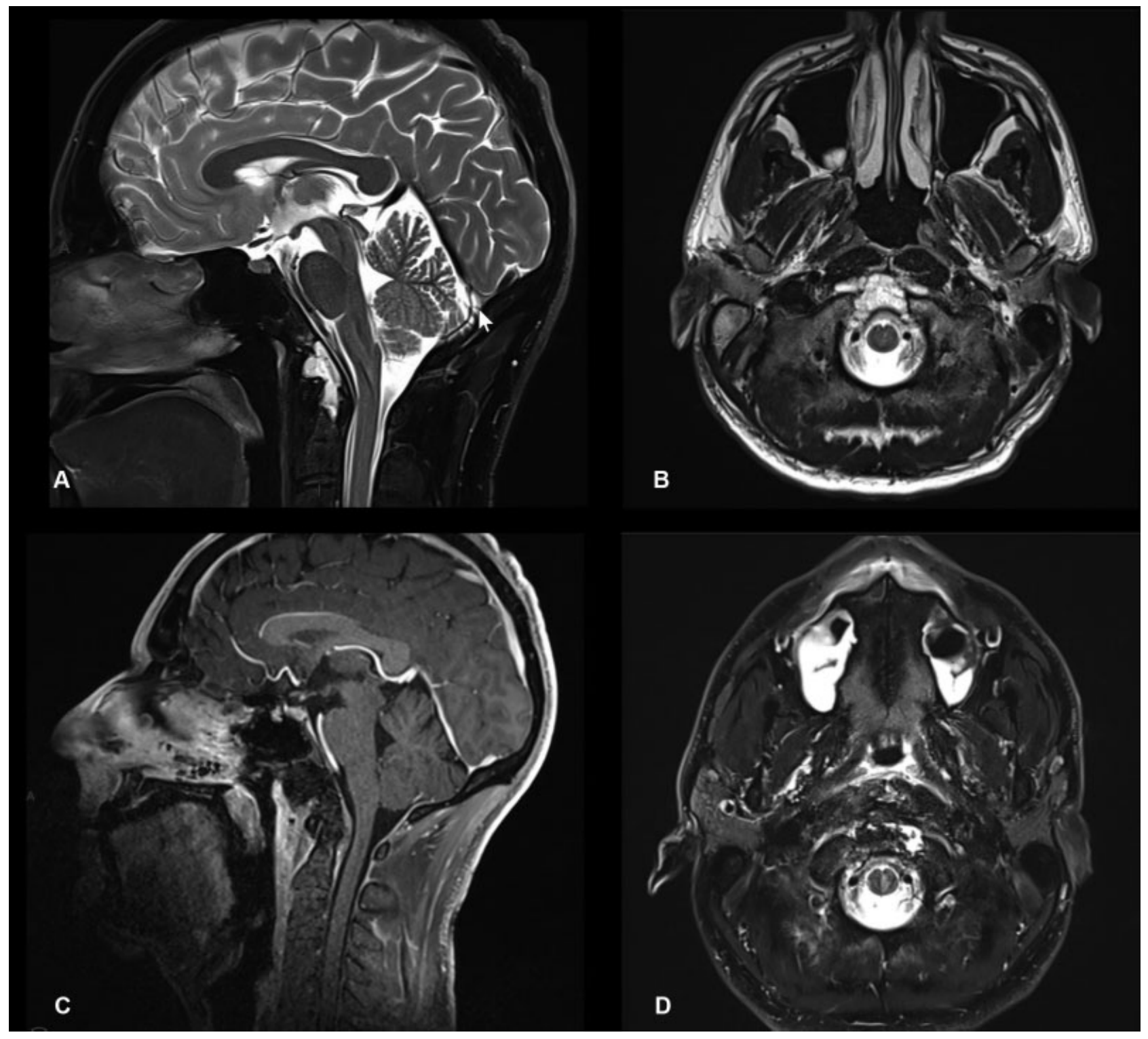

Fig. 1 Pre- and postoperative images of the craniocervical junction chordoma. (A) It shows a preoperative sagittal T2-weighted MRI image. (B) It shows a preoperative axial T2-weighted MRI image. Note that a T2-hyperintense lesion is located in the lower clivus and the odontoid. (C) It shows the postoperative sagittal T1-weighted gadolinium enhanced MRI image. (D) shows a postoperative axial T2-weighted MRI image. These images show the fat graft used for closure, but no evident tumor remnant. MRI, magnetic resonance imaging 


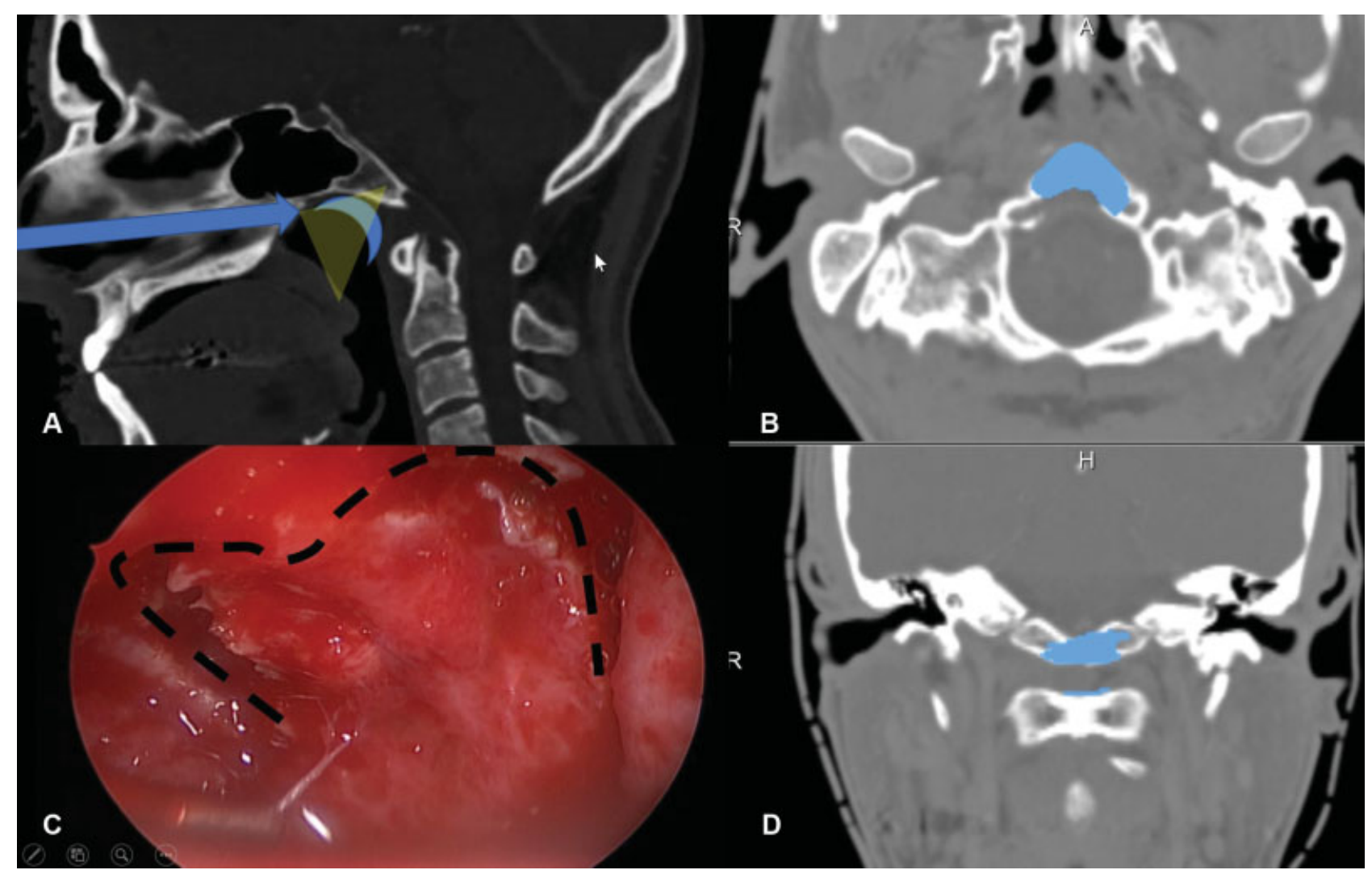

Fig. 2 Illustration of the endoscopic endonasal surgical technique. (A) It shows the surgical route (blue arrow), and location of the heart-shaped mucosal flap that was made in the upper nasopharynx (blue crescent). This figure highlights that angled endoscopes are needed to visualize the relevant operative field (yellow translucent triangle). (B) shows the axial view, (C) shows an intraoperative endoscopic view of the incision performed to achieve a heart-shaped mucosal flap, as was utilized during this case, and (D) shows the coronal view. (B and D) They show the results of postoperative image analysis, during which we segmented the drill cavity (in blue) and projected it on the preoperative CT scan of the patient. Note that besides the inferior clivus, the superior part of the ring of $\mathrm{C} 1$ was also drilled slightly to reach the tumor in the odontoid. $\mathrm{CT}$, computed tomography. 